\title{
Fifteen Uninterrupted Years of Maternal Mortality Findings from a Tertiary Care Centre
}

\author{
Ashma Rana, ${ }^{1}$ Junu Shrestha, ${ }^{2}$ Suvana Maskey, ${ }^{1}$ Sudeep Kaudel, ${ }^{3}$ Prashant Shrestha, ${ }^{4}$ Neeta Katwal, ${ }^{1}$ Pooja \\ Paudyal,' Apariharya Rana ${ }^{5}$ \\ 'Department of Obstetrics and Gynaecology, Tribhuvan University Teaching Hospital, Maharajguni, Kathmandu, \\ 2Department of Obstetrics and Gynaecology, Manipal College of Medical Sciences, Pokhara, ${ }^{3}$ Narayani Samudayik \\ Hospital, Chitwan, ${ }^{4}$ Scheer Memorial Hospital, Banepa, ${ }^{5}$ Aatmiya Community Hospital, Sindhuli, Nepal.
}

\section{ABSTRACT \\ Introduction}

Maternal mortality reflects reproductive health status and availability of good health care facilities at different levels of the healthcare system at a given period, influenced by globally adopted safe motherhood policies. The leading causes of maternal death in Nepal mainly comprise of hemorrhage, eclampsia, abortion-related complications, gastroenteritis and anemia. Although a declining trend has been noted in Nepal it has yet to meet the target set by the Sustainable Development Goal 3.1 of reducing the global maternal mortality ratio to less than 70 maternal deaths per 100,000 live births by 2030 .

\section{Methods}

A cross-sectional study was conducted in the Department of Obstetrics and Gynaecology, Tribhuvan University Teaching Hospital from 1st Baisakh 2055- 30th Chaitra 2069 (15th April 1998- 14th April 2013). The study period of 15 years was divided into three parts, five years each: 2055-59 (14th April 1998-April 13th 2003) ; 2060-64 (14th April 2003- April 12th 2008) and 2065-69 (April 13th 2008 -April 12th 2013). Maternal mortality was filled in performa, discussed in morning conference and maternal mortality audit, computerized, analyzed, presented quarterly and yearly. Annual Maternal Mortality Ratio expressed as MMR per 100,000 live births is calculated by dividing recorded (or estimated) maternal deaths by total recorded (or estimated) live births in the same period and multiplying by 100,000.

\section{Results}

Total maternal mortality ratio in the first, mid and last five years were 39 (270 \%); 37 (212\% ) and 37 (188\%) respectively giving overall total maternal mortality ratio of $113(223.5 \%)$ attributing to Direct: 55 ( $48.6 \%)$, Indirect: 44 (38.9\%) and Non maternal deaths: 14 (12.3\%). Predominating cause of maternal mortality in the first/mid/last five years were sepsis and infective hepatitis each (17.6\%) and PPH (18.5 \%). While SP/E were almost same over the years, in decreasing trend were hepatitis and puerperal sepsis but in rising trend was PPH and criminally induced abortion (10.6\%). The number of maternal death has not changed much, the median age in each five years is surprisingly similar, set at 25 years and the adolescents who died were not very different in every five years. It's unfortunate that many primigravida died during this period which is a matter of concern.

\section{Conclusions}

Maternal mortality stresses the impact of timely health seeking behaviour and health providers making provision of prompt adequate services and referral to help so that all Nepalese mothers, especially the young and first-time pregnant thrive.

Keywords: infective hepatitis; maternal mortality; maternal mortality ratio; PPH; sepsis.

Correspondence: Dr. Ashma Rana (Retd), Department of Obstetrics and Gynaecology, Tribhuvan University Teaching Hospital, Maharajguni, Kathmandu, Nepal. Email: ashmarana2011@gmail. com, Phone: +977-9851048763. 


\section{INTRODUCTION}

Maternal mortality (MM) reflects reproductive health status and availability of good health care facilities at different level of health system, at a given period, influenced by the appropriate safe motherhood policies. Currently, MM in Nepal is declining. ${ }^{1}$ It is imperative to learn whether this reduction in $\mathrm{MM}$ is translated at the institutional level at the same pace. After all, serious cases are received in tertiary care centers like university teaching hospitals. Influenced by projected MM study findings of five to eleven years from other university hospital of different countries, this study aims to explore attributes to MM over 15 years period. ${ }^{2-7}$

\section{METHODS}

This study was conducted in the Department of Obstetrics and Gynecology, Tribhuvan University Teaching Hospital (TUTH), Kathmandu, Nepal, during a study period of 15 years from Nepali calendar BS $1^{\text {st }}$ Baisakh 2055- 30 ${ }^{\text {th }}$ Chaitra 2069 (15 $5^{\text {th }}$ April 1998- $14^{\text {th }}$ April 2013) which was equally divided into the first five year period; $2055-59$ (14 $4^{\text {th }}$ April 1998-April $\left.13^{\text {th }} 2003\right)$, mid; $2060-64$ (14 ${ }^{\text {th }}$ April 2003- April 12 $\left.{ }^{\text {th }} 2008\right)$ and last 5 years period; 2065-69 (April 13 ${ }^{\text {th }} 2008$-April 12 ${ }^{\text {th }} 2013$ ). To begin with, in the first six years only Faculty/ Interns were involved. Thereafter Post Graduate Residents enrolled in MD Obstetrics and Gynaecology, were assigned MM and near miss presentations quarterly/ anually. MM occurring from emergency (ER), labour room, maternity ward, ICU/CCU, neuro ward, burn ward were prospectively followed, Performa was filled, and maternal death audit was done in the following morning conferences to verify the cause of maternal death. This was based on Maternal Deaths Classification [ICD 9 (WHO 1975): Direct maternal death is the result of a complication arising from interventions, omissions or incorrect treatment or from a chain of events resulting in maternal death during the pregnancy, labour and the puerperium. Indirect maternal death is one which is unrelated to pregnancy but is aggravated by the physiological effects of pregnancy in previously existing disease or a newly developed illness diagnosed during pregnancy. Non-obstetrical maternal death is one which is unrelated to pregnancy but occurs during pregnancy from accidental or incidental causes. Each maternal death was discussed in detail, rectifying information and corrected data were entered for detailed analysis at Quarterly-Annual. Yearly Maternal Mortality Ratio (MMR) was calculated by dividing recorded maternal deaths by total recorded live births in the same period and multiplying by 100,000 and expressed as MMR per 100,000 live births

\section{RESULTS}

MM per anum varied from the lowest at 3 in 2060 (April 14, 2003 - April 12, 2004) to highest MM of 15 in 2065 (13 ${ }^{\text {th }}$ April $2008-12^{\text {th }}$ April 2009) Figure 1. Total $\mathrm{MM} / \mathrm{maternal}$ mortality ratio

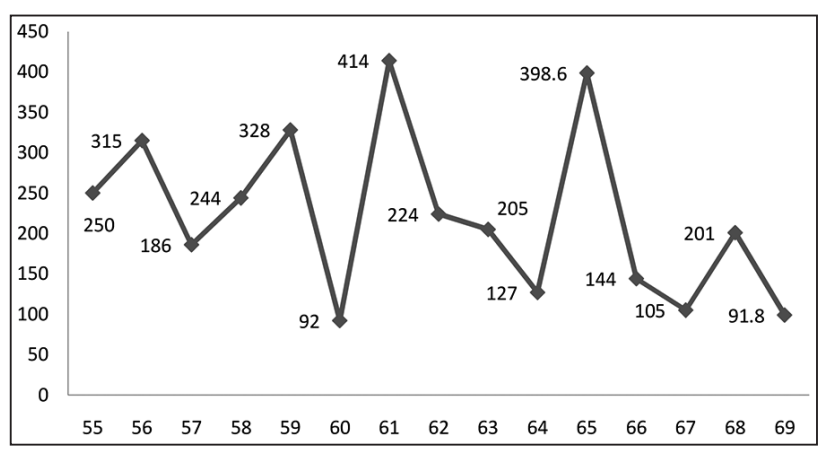

Figure 1. Maternal mortality trend 2055-2069.

(MMR) in the first, mid and last five years were $39(270 \%) ; 37(212 \%)$ and $37(188 \%)$ respectively giving overall total MM/MMR 113 (223.5\%) thus attributing to Direct, Indirect and Non-obstetric/ Non maternal deaths as 55 ( $48.6 \%), 44$ (38.9\%) and $14(12.3 \%)$ (Table 1$)$. 
Table 1. Maternal mortality causes .

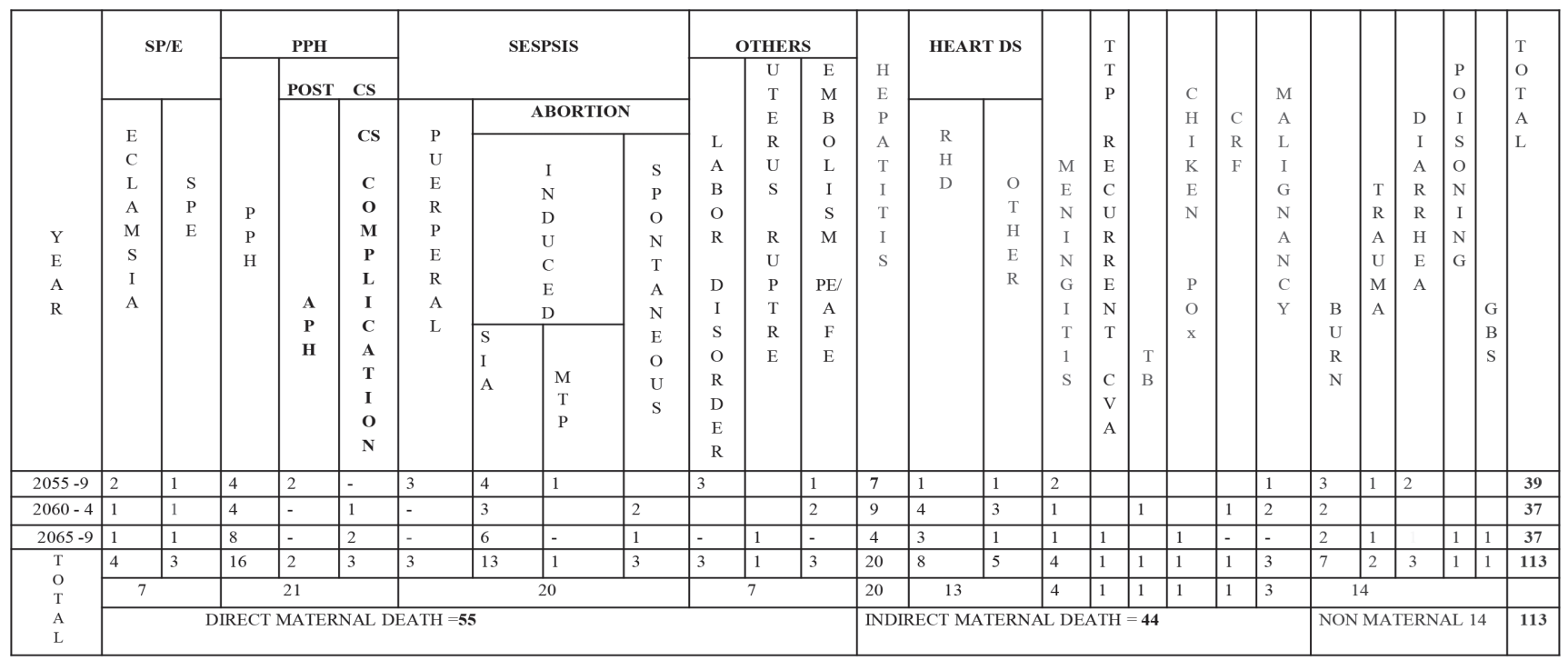

Predominating cause of MM in the first five years was Sepsis. Hepatitis -hepatic failure and hepatic encephalopathy being prime cause of MM mid five years. In the last five years, $\mathrm{PPH}$ was the main cause of $\mathrm{MM}$ and also topped in overall mortality with $21 \mathrm{MM}$ followed by sepsis and infective hepatitis with equal number of MM 20 each. While SP/E were almost same over the years. In decreasing trend were hepatitis and puerperal sepsis but in rising trend was PPH and criminally induced abortion 12: $\{4$ (2055-59); 3 (2060-64) and 5 [2064-69]\} probably performed at second trimester of pregnancy essentially after sex determination but documented only in one case.

Uniform distribution of age and gravida (Figure 2-3) was seen throughout, while primigravidas were more vulnerable to mortality.

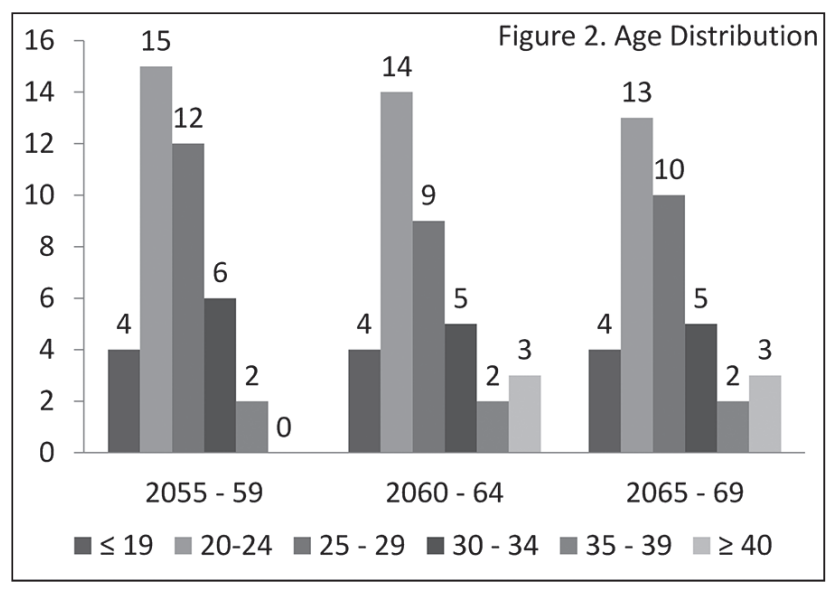

Figure 1. Age in MM 2055-2069 BS.

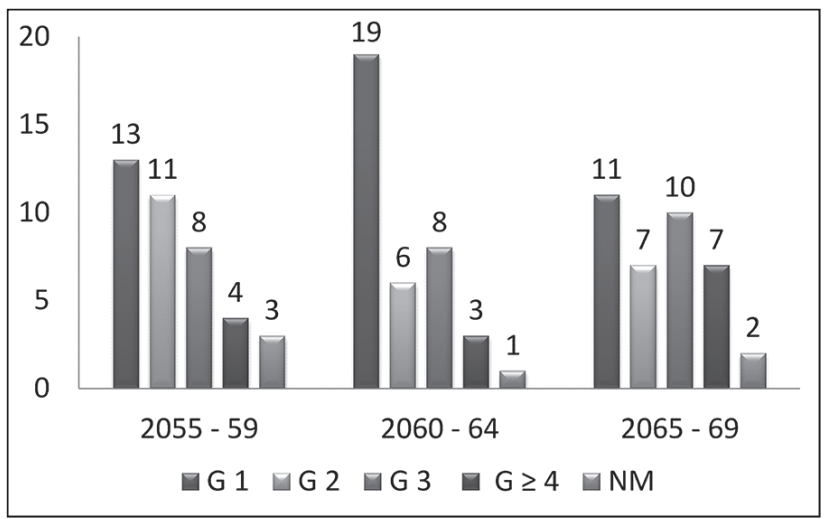

Figure 3. Gravida in MM 2055-2069 BS.

Direct maternal death were 55 (48.6\%) : formed by PPH: 21 ((18.5 \%)); sepsis: 20 ( 17.6\%), Severe preeclampsia and eclampsia (SP/E) :7 (6.1\%); postpartum collapse from labour disorder: $3(2.6 \%)$, amniotic fluid embolism: 2 (1.7\% ), pulmonary embolism $(0.8 \%)$ and uterine rupture:1 (0.8\%).

\section{POSTPARTUM HAEMORRHAGE (PPH)} made by Primary PPH (16) and secondary PPH (5). There were five cases of home delivery with $\mathrm{PPH}$, rest were hospital delivery. In home delivery, four were secondary PPH except for only one case of Primary PPH with retained placenta (RP), who reached our hospital in $2 \mathrm{~h}$ but because of profuse bleeding died then and there in ER. Other case of home delivery 
with RP attended hospital in $19^{\text {th }}$ postpartum day. Altogether, there were three cases of RP, additional one from hospital delivery, in a case of abruption placentae that failed manual removal of placenta (MRP) and was tackled by uterine exploration removing whole placenta in piecemeal. This was a preterm abruption with intrauterine fetal death (IUFD) and spontaneous preterm vaginal delivery of stillborn similar to other abruptio and differed as the latter expelled incomplete placenta with retroplacental clots (250 gm) owing to its association eclampsia, the remaining placental tissue being removed under anesthesia. Third abruptio underwent CS that ended in cesarean hysterectomy $(\mathrm{CH})$ but further needed second laparotomy for intraperitoneal hemorrhage due to disseminated intravascular coagulation (DIC). All these are example of antepartum hemorrhage (APH) as antecedent cause of PPH as illustrated through next case of APH (placenta previa) - PPH - relaparotomy. As outlined, responsible for $\mathrm{PPH}$ were four cases of $\mathrm{APH}$, two of them being a part of post CS complication. There were three more post CS $\mathrm{PPH}$ all of them needed relaparotomy.

The first case had undergone elective CS for cephalopelvic disproportion (CPD) and $11 \mathrm{~h}$ of primary surgery, emergency laparotomy was undertaken with the finding of $2 \mathrm{~L}$ hemoperitoneum, 300gms of clot which up on removal clarified oozing from left uterine angle with huge bilateral haematoma on both uterine angles with multiple lacerations extending from left uterine angle vertically down. Subtotal hysterectomy was done for uterine atony but on after the completion of surgery was declared dead on OT (DOT).

In the second case, Emergency (Em) CS was done for fetal distress delivering a $2.8 \mathrm{~kg}$ live baby complicated by gross abdominal distension and anuria. On opening abdomen 2 days later, $1 \mathrm{~L}$ hemoperitonium amidst huge expanding right (Rt) broad ligament hematoma $8 \times 10 \mathrm{~cm}$ extending from uterine angle retroperitoneally upward towards lumber region into $15 \times 15 \mathrm{~cm}$ mass was found. So Subtotal Hysterectomy for flabby uterus 12 -14 week size was undertaken which on cut section contained 200 gm of clots in the endometrial cavity. Unfortunately, mortality occurred in $81 / 2 \mathrm{~h}$.

In the third and final post CS PPH, peritoneal lavage of $500 \mathrm{ml}$ blood and 500 gm clots arising from multiple oozing near the left angle of lower uterine segment (LUS) incision thereafter securing hemostasis in one who had undergone Em CS for non-progress of labour and Em relaparotomy with multi-organ failure that resulted in maternal death on day 54, ascribed as late maternal mortality

Upper limit of 3.8L PPH at CS was confronted in a previous CS with preterm premature rupture of the membranes (PPROM) and severe oligoamnious is detailed as a bleeding that began right from the beginning from opening the abdomen, extracting the baby as breech cutting through the placenta and thereafter while removing the adherent placenta, urging to go ahead for $\mathrm{CH}$ which after completion ended in DOT.

A peripartum subtotal hysterectomy needs mention here, which was done for massive $\mathrm{PPH}$ from vaginal tear following spontaneous vaginal delivery in 20 years primigravida who succumbed to death within 24 hours.

Total CH: 7 [ Post CS for APH: 2: [abruptio (1)+ placenta previa (1)] ; post CS complications: (3); PPROM -oligoamnious (1) and vaginal tear following vaginal delivery (1)] Timing of hysterectomy for PPH-CH were per-operative:2 [ abruptio (1); oligoamnious with PPROM (1) ]; within 12h:2[ Post CS for CPD (1) and vaginal tear (1)] and rest were after 24-48h (3). There were two DOT, one each in reopened CS for 
CPD and one for oligoamnious with PPROM and adherent placenta accreta. Relaparotomy was done in all post CS complication inclusive of APH-PPH.

Massive transfusion was given in all cases of CS complications with PPH. Maximum blood and blood products transfused were up to 7 unit whole blood, 12 units (U) fresh Blood, 5 FFP, 17 platelet rich plasma. PRP.

Primary $\mathrm{PPH}$ was aggravated by other conditions like hepatitis (4), more when the labour was induced for hepatitis in preterm pregnancy and IUFD (2). Conservatively awaited PPROM in post percutaneous transvenous mitral commissurotomy (PTMC) -RHD proved detrimental on assisted breech vaginal delivery. Intervention in form of exploration of uterus in primary or secondary PPH and retained placenta undergoing manual removal or piecemeal retrieval were associated with sepsis as comorbidity. Pulmonary embolism (PE) and one of two cases of amniotic fluid embolism (AFE) were associated with $1.5 \mathrm{~L} \mathrm{PPH}$ being detailed below.

Sepsis essentially formed by MTP (1), septic sequel of spontaneous abortion (3), puerperal sepsis (3) and by and large by septic induced abortion (13), comprising mainly the surgically interfered ones were detrimental. Repeated attempts at evacuation (3) proved fatal on account of visceral trauma. Enumerated are SIA tried twice in two cases, one of the two case had laminaria tent insertion and died of brain abscess. The other case who underwent second attempt of D\&C, sustained uterine perforation and sigmoid injury was surgically treated by total abdominal hysterectomy and colostomy. Last of all, a case exposed to four attempts of uterine curettage, at laparotomy contained 2L of pyoperitoneum and mesenteric necrosis. Pyoperitoneum 2L were also seen in two more
SIA, one who having had gangrenous gut was treated by subtotal hysterectomy with resection and anastomosis of the intestine, the other developed ARF and was treated by dialysis. Maximum amount of dirty peritoneal fluid equal to $4 \mathrm{~L}$ was seen in jejeunal perforation repaired surgically together with peritoneal lavage. Whereas uterine perforation that occurred along with ideal injury were two in number and both underwent subtotal hysterectomy and ileal resection and anastomosis, unfortunately need for laparotomy and drainage of $500 \mathrm{ml}$ of pus was necessitated in one of them. Last of all, fetus floating in 5L of hemoperitoneum was seen in an additional case of posterior uterine rent with injury in rectosigmoid junction and injury at the bifurcation of right common iliac vein which was managed by complex reparative surgery and colostomy.

To summarize, uterine perforation occurred in four cases and except one that was repaired, all the three underwent hysterectomy [total hysterectomy (1) and subtotal (2). In addition, fourth case of subtotal hysterectomy was done in gangrenous gut without uterine trauma.

Deterioration of the maternal conditions were brought about by septic shock, adult respiratory distress syndrome (ARDS), acute renal failure (ARF) with creatinine value as high as $437 \mathrm{~mm}$ /L and high value of bilirubin $224 \mathrm{mmol} / \mathrm{L}$ in hepatorenal syndrome. Seriousness of puerperal sepsis was seen with high-grade fever up to 106 degree, unconsciousness due to intracranial thrombosis, cerebral venous thrombosis augmented by late admission on post-partum day 6- 19 in puerperal sepsis.

SP/E (3+4): Of the four cases of eclampsia only one was antepartum rest were postpartum. Their presentation were like rupture of previous CS scar, facial palsy, quadriparesis, renal failure and hyponatremia ( $\mathrm{Na} 111$ ) that worsened the 
prognosis. Severe preeclampsia (3) of which two were complicated by HELLP ( Hemolysis, Elevated Liver enzymes, and Low Platelet count ) syndrome and one of two, with cumulative effects of high dose of antihypertensives resulted in hypotensive insult and unrecordable BP. The third case of SP was superimposed on chronic hypertension with BP 240/130 mm Hg and hypertensive crisis thus complicated by supraventricular tachycardia.

Postpartum collapse had a significant contribution and were adhered to errors in labour management disorder observed as pulling out preterm baby by ventouse through partially dilated cervix (2), beginning initially by ventouse application to dilate the undilated cervix and once fully dilated switching over to forceps application (2) or waiting for more than $8 \mathrm{~h}$ of full cervical dilation presuming a preterm baby will definitely come out. Also early transfer from labour room to medical ward while patient were having shortness of breath were also equally culpable.

Direct maternal death included a case of pulmonary embolism (PE) and two cases of amniotic fluid (AFE). First case of AFE gave history of 3 days of leaking and had antepartum collapse, when subjected to CS, there was occurrence of DOT, with there were three DOT. Next was a case of postdated pregnancy at $41+5$ weeks, primed with two doses of dinoprostone (cerviprime) gel and augmented with syntocinone who after $2 \frac{1}{2} \mathrm{~h}$ of artificial rupture of membrane (ARM) was found gasping, cyanosed, frothing with iv prick sites bleeding developed hypoxic seizure for which endotracheal intubation was done supported by inj adrenalin/ inj dopamine. Instrumental delivery using forceps after failed vacuum gave outcome of alive male baby, $3 \mathrm{~kg}$ with $1.5 \mathrm{~L}$ PPH. CVP measured $6 \mathrm{~cm}$ so iv normal saline, ringer lactate, haemacele, $8 \mathrm{u}$ FFP, $5 \mathrm{u}$ PRP,
$10 \mathrm{u}$ fresh blood were given to counterbalance coagulopathy with laboratory indices of $\mathrm{Hb}$ $5.5 \mathrm{gm} \%$, fragmented RBC in PBS, CT: 10min, PT-120 sec, APTT>150s, platelet: 40000, FDP $>1600<3200$, LDH-4625 U/L, SGOT-158U/L, SGPT-118U/L, Creatinine $-699 \mu \mathrm{mol} / \mathrm{L}$ and CT showing multiple watershed infarcts. For Acute renal failure (ARF) 7 cycles dialysis was done. Tracheostomy done on $9^{\text {th }}$ PPD but died on $27^{\text {th }}$ day due to multiorgan failure (MOF)

Rupture of the uterus in a G2 P1 with previous CS for big baby and obstructed labour managed outside by laparotomy at 39 weeks and referred postoperatively for uroperitoneum, on relaparotomy showed leaking from ureteric laceration in the proximal part. Presumed to have occurred iatrogenically during exploration of ureter while repairing ruptured uterus. DJ stenting and repair of the ureter was done with unfortunate mortality in $3^{\text {rd }}$ postoperative day.

To summarize, including above case there were total seven cases of relaparotomy, post CS PPH: 5 and a case of SIA for the drainage of $500 \mathrm{ml}$ of pus following subtotal hysterectomy with ileal resection and end-to-end anastomosis.

At the same time nine hysterectomies were done. SIA (4) and PPH: 5 dduring CS for PPROM (1), Post CS - for abruptio (1) and Post simple CS: 2 [for CPD (1) and Fetal distress (1)]\}

Three laparotomy were done entirely for SIA: $1^{\text {st }}$ - pyoperitoneum of $2 \mathrm{~L}$ in mesenteric necrosis (1); $2^{\text {nd }}$ jejunal perforation with $4 \mathrm{~L}$ of dirty fluid and last was uterine rent with extruded fetus floating in 5L of hemoperitoneum with iliac vessel injury respectively.

Deaths in the OT table were three in number; one resulted from intrapartum torrential bleeding at CS that was advanced to $\mathrm{CH}$ undertaken for PPROM. Second was at CS for antepartum collapse, who could not be extubated and lastly at relaparotomy for tackling hemorrhagic 
complication 11 hours following EL. LSCS for CPD.

Indirect maternal death: $44(38.9 \%)$ by and large was caused by hepatitis 20; heart disease 13: $(11.5 \%)$ [ RHD: $8(7 \%)$; others 5 (4.42\%) inclusive of two cases of aortic diessction rest were carditis and heart failure. Other causes of indirect maternal death were meningitis: 4 (3.5\%); malignancy 3: [pulmonary mesothelioma (1), acute myeloid leukemia (1) and intracranial tumor (1)] along with one case each of Thrombotic thrombocytopenic purpura (TTP) with recurrent cerebrovascular accident (CVA), disseminated tuberculosis, chronic renal failure and chicken pox.

Infective hepatitis classically presented with Few days of fever (temperature up to 105 degree), jaundice, high colored oily scanty urine, disorientation, pre-coma and coma embracing high mortality in 11 (HEV) positive cases. There was significant alteration in biochemical/ hematological parameters, low RBS $0.7 \mathrm{~m}$ $\mathrm{mol} / \mathrm{L}$, TLC $=40,000 / \mathrm{cmm}$, deranged LFT as marked by raised bilirubin up to $458 \mu \mathrm{mol} / \mathrm{L}$, LDH -1268 U/L, AST - 1730 U/L, ALT -1153 IU/L, SGOT -1180 U/L, creatinine $892 \mathrm{mmol} / \mathrm{L}$. Except for a case, admitted post-partum all the rest were antepartum ending in abortion (1) or preterm pregnancy with IUFD, mother dying with undelivered dead fetus in utero (n-2) due to coagulation disorder Prothrombin Time $\geq$ 100 seconds. Hepatic failure arising from liver cirrhosis presented with hematemesis needing gastric banding to prevent bleeding from esophageal varices.

Besides the two cases of aortic dissection one of them had undergone Bentall operation within two weeks postpartum, majority were rheumatic in origin RHD with multivalve involvement. Surgical procedure undertaken were post- percutaneous transvenous mitral commissurotomy (PTMC)/percutaneous mitral balloon valvotomy $\mathrm{n}=3$ : [past (2) and index pregnancy (1)]. MM was related to vegetation on valves in two cases on warfarin one post MVR and ASD closure.

Non-maternal death:14(12.3\%) were essentially formed by flame burn -7 (one suicidal), diarrhea (3), trauma: 2 [1- RTA and 1- due to fall with C6/7 injury]; Organophosphorus poisoning (1) and 1 case of Guillain-Barre Syndrome (GBS).

\section{DISCUSSION}

This is perhaps one single study covering a period of fifteen years, while most studies on MM from university hospital have been carried maximum up to 11 years. ${ }^{3}$ Contributory cause of $\mathrm{MM}$ were found to be hemorrhage, sepsis and infection with change of sequential order in different university hospital. ${ }^{2-7}$ Sepsis, unsafe abortion, obstetric hemorrhage - placenta praevia, PPH, ectopic pregnancy, HDP ( PE /E;), HIV/AIDS infection, malaria, anemia, heart disease and pneumonia were causes of MM. ${ }^{2-8}$ Infective hepatitis unlikely is not so rampant elsewhere. $^{9}$

The number of maternal deaths has not changed much in our study. The median age in each five years is surprisingly similar, set at 25 years and the adolescents who died were not very different in every five years. It's unfortunate that many primigravida died during this period which is a matter of concern. Averting $\mathrm{MM}$ is not by combating with dreadful complications, but by not letting them happen in the first place. Half of the time goes frantically looking for blood and blood products like PRP, FFP, fresh blood or whole blood in abundance like in $\mathrm{PPH}$ with coagulopathy and DIC, consumptive coagulopathy like abruptio or dilutional coagulopathy as in severe blood loss in PPH, vaginally or abdominally or sometimes entrapped in deceptive hematoma. 
PPH often precipitated by deranged liver parameters, provoked by hepatitis, IUFD, HELLP Syndrome. Therefore, availability of blood and blood products must be ascertained beforehand whenever PPH is anticipated. This is derived from our study in which $\mathrm{PPH}$ like other countries is leading cause of MM. ${ }^{3,5,10} \mathrm{MM}$ 21 (18 \%) from PPH could have been minimized by keeping careful watch, awareness and preparedness. PPROM and chorioamnionitis, especially when confounded with IUFD appears dreadful combination as atonicity by former being adjunct to coagulation failure from latter. Inducing labour for IUFD alone or in combination with PPROM have proven fatal. Alerting the unforeseen complication of $\mathrm{PPH}$ at home delivery is essential as maternal death have occurred within instantly or minutes of arrival complicated with or without retained placenta. Also equally necessary is to keep the possibility of re-laparotomy as second operation after $\mathrm{CS} / \mathrm{CH}$ especially in all preceded by $\mathrm{APH}$ as placenta previa, placenta sitting over lower uterine segment devoid of contractile myometrial muscle or abruptio closely linked with coagulopathy / DIC with possibility of hemoperitoneum. To timely combat the situations adequately, obstetrician with expertise on $\mathrm{CH}$ must be in the vicinity, while cesarean is going on, looking for consultant during dire decision making hours has proven fatal. On the other hand, let us adhere to continuing the lost practice of monitoring postpartum mother and make sure to shift them only after they pass good amount of urine, which signifies hemodynamic stability and renal perfusion. Two mother lost their life with late detection of multiple vaginal tear and cervical tear laceration, latter combined atonicity. Even peripartum hysterectomy: n-4 $[\mathrm{PPH}$ management following vaginal tear (1) and cesarean complication (2) and abruptio CS followed $-\mathrm{CH}(1)$ ] proved futile, and not to any advantages. Five of nine hysterectomies were done for PPH and CS complications while rest were performed for septic abortion.

Sepsis related MM (17.6\%) is similar to one study but unimaginable in this era. ${ }^{4,11} \mathrm{MM}$ was found to be incorporated with unsafe abortion, mainly illegally induced septic abortion in second trimester after sex determination with disastrous confrontation of uterine and gut perforations resulting in significant pyoperitoneum and brain abscess. Septic sequel of spontaneous abortion and MTP also met fatal fate, a lesson learnt to avoid insertion of foreign body like laminaria tent during fever, to procure illegal abortion. There are reasons to believe that the induced septic abortion was the main culprit in the causation of preventable maternal $\operatorname{loss}^{7,8}$. Clandestine abortions were heavily practiced before the legalization abortion in Nepal. On the other hand puerperal sepsis has been recognized as known culprit for fatality, especially after days of retention of placenta/placental tissue adversely worsened by acquiring late admission and furthermore, retained placenta, being removed shortly thereafter without giving ample time for antibiotics to work. As more serious cases are received at the institution in the terminal state, many of them die within minutes to hours of arrival, Therefore adherences to the principles of $4 \mathrm{C}$, which is clean blade, clean cord, clean tie and clean delivery place, maintaining hygiene during pregnancy and delivery must be appropriately practiced at all times, on the cover of proper antibiotic if needed.

Death from SP/E can be averted, first by regular antenatal care (ANC) measuring BP and urine for albumin, and timely referral of complicated SP/E by HELLP Syndrome. Loading IM dose of magnesium sulphate must be given before referring SP/E. While controlling hypertension, cautions against overloading multiple 
antihypertensive must be negated as this has led to death from irreversible hypotensive shock stat or in ICU. ${ }^{12}$

Intrapartum care is another area of great concern and this important message is aimed to be hopefully dissipated through this study. Proper labour management calls for, not to keep continuing prolonged second stage under the pretext of a preterm baby that is hoped to come out eventually with no issue of CPD as doing so death resulted from consequences of prolonged labour and hyperkalemia. Also not to use ventouse in preterm baby and start pulling from $6 \mathrm{~cm}$ dilated cervix or use ventouse simultaneously together with forceps deliberately to expedite delivery, ventouse to aid in cervical dilatation so that forceps can be used to deliver the baby, a wrong practice. Also never ever transfer postpartum mother with shortness of breath from anemia doubled with respiratory issues, within an hour of birth, such a disastrous step have resulted in maternal loss in within 1-2 hours in two cases.

Coming to indirect $\mathrm{MM}$, its sad how parents get their daughters married off without treating their pre-existing cardiac conditions leading to their husbands making their ailing wives pregnant without perinatal counselling. One such example concerns a young mother with severe mitral stenosis and atrial fibrillation who died during admission procedure for MTP. This entreats the need for societal education on basic pregnancy health issues.

Infective hepatitis was surprisingly identified as the main cause of MM in mid five years, sharing equal results with maternal sepsis and very close to $\mathrm{PPH}$ in causing overall maternal deaths. It was almost like an epidemic as there were numerous cases of maternal deaths from acute fulminant hepatitis, some antepartum deaths and few post-partum deaths occurring before their preliminary lab results were ready. ${ }^{9}$ Finally, maternal death primarily from infection such as infective hepatitis and secondly sepsis related to puerperal sepsis, induced abortion and septic sequelae of spontaneous abortion and MTP along with carditis/endocarditis with mural vegetation, meningitis (instigated by (SOM), disseminated tuberculosis, sepsis from burn and gastroenteritis is depreciative. Moreover, let us prevent RHD and related MM by timely diagnosis and treatment of sore throat in the childhood.

\section{CONCLUSIONS}

Maternal mortality stresses the crucial role of timely health checkups in significantly reducing fatalities and the imperative of providing for prompt and adequate services to all Nepalese mothers, especially those younger and newly expectant. Preventing this is a matter of basic natal health awareness, encouragement by the family to seek appointments, the primary facilities being sufficiently staffed and equipped with the practice of timely referral. Safe motherhood should be the norm for Nepalese mothers as it is in developed nations where non-fatal pregnancies are routine.

\section{ACKNOWLEDGEMENTS}

Bekha Manandhar, Bharati Devi Sharma, Baroon Rai, Kum Kum Vadera, Meghna Tiwari, Sapna Amatya, Isha Shrestha, Anupama Goel, Anju Deo, Varsha Nathani, Monika Yadav, Basant Lamichhane, Suresh Kayastha. 


\section{REFERENCES}

1. Hussein J, Bell J, Iang MD, Mesko N, Amery J, Graham W. An appraisal of the maternal mortality decline in Nepal. PLOS One [Internet]. 2011 May 26 [cited 2011 Jun 30];6(5):e19898. Available from: https://journals.plos.org/plosone/ article?id=10.1371/journal.pone.0019898 DOI: 10.1371/journal.pone.0019898

2. Obiechina NJ, Okolie VE, Okechukwu ZC, Oguejiofor CF, Udegbunam OI, Nwajiaku LS, Ogbuokiri C, Egeonu R. Maternal mortality at Nnamdi Azikiwe University Teaching Hospital, Southeast Nigeria: a 10-year review (2003-2012). Int J Womens Health [Internet]. 2013 Jul 23 [cited 2015 Sep 28];5:431-6. Available from: https://www.dovepress.com/ maternal-mortality-at-nnamdi-azikiweuniversity-teaching-hospital-sout-peerreviewed-fulltext-article-IJWH DOI: 10.2147/ijwh.s46988

3. Agan TU, Archibong EI, Ekabua JE, Ekanem EI, Abeshi SE, Edentekhe TA, Bassey EE. Trends in maternal mortality at the University of Calabar Teaching Hospital, Nigeria, 1999-2009. Int J Womens Health [Internet]. 2010 Aug 10 [cited 2011 Sep 9];2:249-54. Available from: https://www.dovepress.com/ trends-in-maternal-mortality-at-theuniversity-of-calabar-teaching-hos-peerreviewed-fulltext-article-IJWH DOI: 10.2147/ijwh.s11971

4. Olamijulo JA, Olorunfemi G, Olaleye $\mathrm{O}$, Ogedengbe OK, Giwa-Osagie OF. Trends in maternal mortality at the Lagos University Teaching Hospital, Lagos, Nigeria. Nig Q J Hosp Med [Internet].
2012 Apr-Jun [cited 2017 Oct 6];22(2):72-

9. Availabe from: https://pubmed.ncbi. nlm.nih.gov/23175901/.

5. Tebeu PM, Halle-Ekane G, Itambi MD, Mbu RE, Mawamba Y, Fomulu JN. Maternal mortality in Cameroon: a university teaching hospital report. Pan Afr Med J [Internet]. 2015 May 7 [cited 2015 Dec 16];21:16. Available from: https://panafrican-med-journal.com/ content/article/21/16/full/. DOI: 10.11604/ pamj.2015.21.16.3912

6. Aboyeji AP, Ijaiya MA, Fawole AA. Maternal mortality in a Nigerian teaching hospital - a continuing tragedy. Trop Doct [Internet]. 2007 Apr 1 [cited 2013 Jan 14];37(2):83-5. Available from: https://journals.sagepub.com/ doi/10.1177/004947550703700207 DOI: $10.1177 / 004947550703700207$

7. Henderson JT, Puri M, Blum M, Harper CC, Rana A, Gurung G, Pradhan N, Regmi K, Malla K, Sharma S, Grossman D, Bajracharya L, Satyal I, Acharya S, Lamichhane P, Darney P D. Effects of abortion legalization in Nepal, 2001-2010. PLOS One [Internet]. 2013 May 31 [cited 2014 May 14];8(5):e64775. Available from: https://journals.plos.org/plosone/ article?id=10.1371/journal.pone.0064775 DOI: 10.1371/journal.pone.0064775

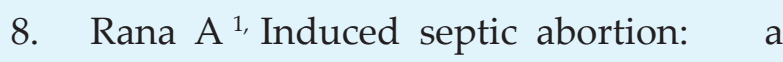
major factor in maternal mortality and morbidity. J Obstet Gynaecol Res. 2004;30(1):3-8. doi: 10.1111/j.13418076.2004.00146.x. PMID: 14718012

9. Rana $\mathrm{A}^{1,}$ Maternal mortality over the last decade: a changing pattern of death due to alarming rise in hepatitis in the latter five- 
year period. J Obstet Gynaecol Res. 2009 Apr;35(2):243-51. doi: 10.1111/j.14470756.2008.00946.x. PMID: 19708172

10. Mpemba F ${ }^{1}$, Kampo, Zhang X. Towards 2015: post-partum haemorrhage in subSaharan Africa still on the rise. J Clin Nurs. 2014 Mar;23(5-6):774-83. Epub 2013 Mar 8. doi: 10.1111/jocn.12126. PMID: 23472972.

11. Kouskouti $\mathrm{C}^{1}$, Evangelatos $\mathrm{N}^{23}$, Brand $\mathrm{A}^{456}$, Kainer $\mathrm{F}^{7}$. Maternal sepsis in the era of genomic medicine. Arch Gynecol. 2018 Jan;297(1):49-60.Obstet. Epub 2017 Nov 4. doi: 10.1007/s00404-017-4584-5. PMID: 29103195.

12. Barros $\mathrm{JFS}^{12}$, Amorim $\mathrm{MM}^{12}{ }^{2}$, Costa $\mathrm{DGL}^{1}$, Katz L ${ }^{12}$. Factors associated with severe maternal outcomes in patients with eclampsia in an obstetric intensive care unit: A cohort study. Medicine (Baltimore). 2021 Sep 24;100(38):e27313. doi: $\quad$ 10.1097/MD.0000000000027313. PMID: 34559147

Citation: Rana A, Shrestha J, Maskey S, Kaudel S, Shrestha P, Katwal N, Paudyal P, Rana A. Fifteen Uninterrupted Years (1998- 2013) of Maternal Mortality Study Findings from Tribhuvan University Teaching Hospital. CMS Nepal. $2021 ; 17(3) ; 241-51$ 